\title{
A COBERTURA DA TERRA E A QUALIDADE AMBIENTAL URBANA DO BAIRRO ALTO (CURITIBA-PR)
}

Paulo Henrique Costa ${ }^{1}$

João Carlos Nucci ${ }^{2}$

Simone Valaski ${ }^{3}$

\section{RESUMO}

O aumento das áreas impermeabilizadas e a consequente redução da vegetação nos bairros dos centros urbanos diminuem a qualidade ambiental. O trabalho teve por objetivo mapear e classificar um bairro em três tipos principais de espaços (espaços não edificados, espaços edificados e espaços de integração viária), visando inferir a qualidade ambiental. Os espaços edificados foram subdivididos quanto ao porte e número de pavimentos e presença ou não de vegetação adjacente. Os espaços não edificados foram classificados de acordo com a estrutura da vegetação (arbórea, arbustiva e herbácea), solo exposto e solo impermeabilizado.O recorte espacial utilizado foi o Bairro Alto na região nordeste de Curitiba-PR, que foi classificado e mapeado em ambiente SIG (ArcView 9.3.1), por meio da interpretação de imagens de satélite (Google Earth) com escala aproximada de 1:5.000. A legenda detalhada, bem como o mapa de cobertura da terra, permitiram a espacialização da qualidade ambiental no Bairro Alto que se apresentou relativamente boa, exceto na porção oeste onde a cobertura da terra condicionou uma baixa qualidade ambiental.

PALAVRAS-CHAVE: Planejamento da paisagem, cobertura da terra, qualidade ambiental.

\section{COVERAGE OF EARTH AND ENVIRONMENTAL QUALITY URBAN NEIGHBORHOOD HIGH (CURITIBA-PR)}

\footnotetext{
${ }^{1}$ Acadêmico de Geografia pela Universidade Federal do Paraná, bolsista Iniciação Científica. Curitiba, Paraná, Brasil. E-mail: henrigeog@gmail.com

${ }^{2}$ Biólogo (IB-USP), doutor em Geografia Física (DG-FFLCH-USP), professor do Departamento de Geografia da UFPR. Curitiba, Paraná, Brasil. E-mail: nucci@ufpr.br

${ }^{3}$ Geógrafa, mestre e doutora em Geografia (DGEOG-UFPR), professora do Setor de Educação Profissional e Tecnológica (SEPT-UFPR). Curitiba, Paraná, Brasil. E-mail: valaski@ufpr.br
} 


\begin{abstract}
The increase in impermeable areas and a consequent reduction in vegetation in the inner city areas decrease environmental quality. The study aimed to map and classify a neighborhood in three main types of spaces (open spaces, built spaces and spaces of roads integration)), to infer environmental quality. The built spaces were subdivided according to size and number of pavements and the presence or absence of vegetation adjacent. The Non-built-up spaces were classified according to the structure of vegetation (arboreal, shrubs and herbaceous), exposed soil and waterproof soil. The spatial area used was the Bairro Alto in the northeast of Curitiba-PR, which has been classified and mapped environment GIS (ArcView 9.3.1), through the interpretation of satellite images (Google Earth) with an approximate scale of 1: 5,000. The detailed legend, and the land cover map, allowed the spatial environmental quality in Bairro Alto that presented relatively good, except in the western portion where the land cover has conditioned a low environmental quality.
\end{abstract}

PALAVRAS-CHAVE: Landscape planning, land cover, environmental quality.

\title{
COBERTURA DE LA TIERRA Y DE CALIDAD AMBIENTAL URBANA BARRIO ALTO (Curitiba-PR)
}

\section{RESUMEN}

El aumento de las áreas impermeables y la consiguiente reducción de la vegetación en las zonas interiores de la ciudad disminuyen la calidad ambiental. El estudio tuvo como objetivo trazar y clasificar un barrio en tres tipos principales de espacios (espacios abiertos, espacios construidos y espacios de integración carreteras)), para inferir la calidad ambiental. Los espacios construidos fueron subdivididos según el tamaño y número de los pavimentos y la presencia o ausencia de vegetación adyacente. Los espacios no urbanizadas, se clasificaron de acuerdo a la estructura de la vegetación (arbóreas, arbustos y herbáceas), suelo expuesto y suelo impermeable. El área espacial utilizado fue el Bairro Alto, en el noreste de Curitiba-PR, que ha sido clasificado y entorno SIG asignada (ArcView 9.3.1), a través de la interpretación de imágenes de satélite (Google Earth) con una escala aproximada de 1: 5000. La leyenda detallada, y el mapa de cobertura de la tierra, permitieron a la calidad del medio ambiente espacial en Bairro Alto que presenta relativamente buena, excepto en la parte occidental, donde la cobertura de la tierra ha condicionado una calidad ambiental baja.

PALAVRAS-CHAVE: Planificación del paisaje, Cubierta del suelo, calidad ambientales.

\section{INTRODUÇÃO}

O crescimento das cidades associado à especulação imobiliária vem ocorrendo com pouca ou nenhuma preocupação com a qualidade ambiental urbana. Lotes residenciais que até anos atrás possuíam grandes áreas com vegetação para fins estéticos, de lazer ou até mesmo para o bem-estar de seus próprios moradores, estão cada vez mais edificados e impermeabilizados, desfavorecendo a atuação de processos naturais fundamentais para a manutenção do meio físico e biológico. 
George (1984) afirma que as últimas casas com hortas pertencentes aos trabalhadores, acabaram por desaparecer sob a pressão da construção e da recuperação dos últimos terrenos livres para serem utilizados como espaços de serviços. Somado a isso, as propostas de adensamento e de expansão urbana são baseadas apenas na disponibilidade de infraestrutura e de espaço físico, não se importando com a qualidade ambiental, tampouco com as outras necessidades dos moradores locais (Nucci, 2008).

Dessa forma, espaços ao ar livre como jardins, parques, bosques e praças estão cada vez mais escassos e encolhidos frente às edificações criadas para atender as demandas econômicas e sociais de uma política imediatista. O que vai contra os argumentos defendidos por Gröning (2004), que ressalta a necessidade da existência de espaços livres que possam satisfazer os múltiplos interesses humanos das mais variadas formas no interior das cidades.

Nesse sentido é necessário que se busquem alternativas para que as cidades sejam pensadas, planejadas e acompanhadas contemplando não só os seus próprios e imediatos anseios, como também, a preocupação com os processos naturais que nela são exercidos.

Tais pressupostos se encontram na teoria do Planejamento da Paisagem que vem sendo empregada principalmente como instrumento preventivo em relação a conservação da natureza em países europeus, desempenhando hoje, um papel importante na área do desenvolvimento ecológico urbano (Del Picchia, 2010).

De acordo com Kiemstedt (1998), inicialmente o Planejamento da Paisagem surgiu impulsionado pelo desejo de embelezamento da paisagem e da tentativa do resgate ao verde que estava sendo dizimado pelas novas práticas consequentes da Revolução Industrial. Aos poucos, a motivação do Planejamento da Paisagem foi ganhando maior apelo ambiental, se preocupando cada vez mais com a conservação da natureza e com o funcionamento dos componentes do meio físico e biótico. Dessa forma, o Planejamento da Paisagem foi se consolidando com o objetivo de manter, de maneira sustentável e duradoura, a capacidade funcional dos ecossistemas e seu aspecto visual (Valaski, 2008). 
Nucci (2008) considera que o Planejamento da Paisagem é um instrumento de preservação e utilização da natureza com o objetivo de salvaguardar a capacidade dos ecossistemas e a potencialidade recreativa da paisagem como partes fundamentais da vida humana.

São várias as formas de se trabalhar com o Planejamento da Paisagem seja para fins educativos, seja para fins de aplicação. Uma das alternativas é a espacialização e posterior avaliação da qualidade ambiental urbana, que segundo Nucci (1996), está relacionada principalmente, com os seguintes aspectos: usos do solo potencialmente poluidores, verticalidade das edificações, densidade demográfica, cobertura vegetal e espaços livres. Nas duas últimas décadas, vários estudos aplicaram o método de avaliação da qualidade ambiental urbana desenvolvido por Nucci $(1996)^{4}$.

Nesse sentido, embora existam vários critérios relacionados com a qualidade ambiental, este trabalho contempla apenas a influência da cobertura da terra, conforme Valaski (2013) e Nucci et al. (2014).

\section{OBJETIVOS}

Classificar a cobertura da terra de cada quadra do Bairro Alto de acordo com a legenda proposta por Valaski (2013) e adaptada por Nucci et al (2014) no intuito de mapear sua qualidade ambiental.

4 Trabalhos que organizaram ou revisaram os estudos que já foram feitos:

TONETTI, E. L. Potencialidade de adensamento populacional por verticalização das edificações e qualidade ambiental urbana no município de Paranaguá, Paraná, Brasil. 2011. 235 f. Tese (Doutorado em Geografia) - Departamento de Geografia, Universidade Federal do Paraná, Curitiba, 2011.

ESTÊVEZ, L. F. Relatórios Ambientais Prévios (RAPs) realizados em Curitiba (PR): uma análise com base nos princípios do Planejamento da Paisagem. $166 \mathrm{f}$. Tese (Doutorado em Geografia) Departamento de Geografia, Universidade Federal do Paraná, Curitiba, 2014. 


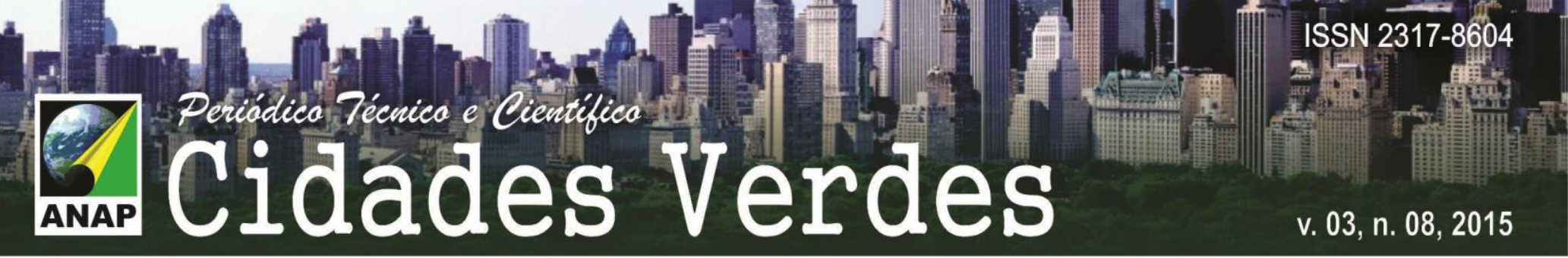

Figura 1: Cartograma de localização do Bairro Alto.

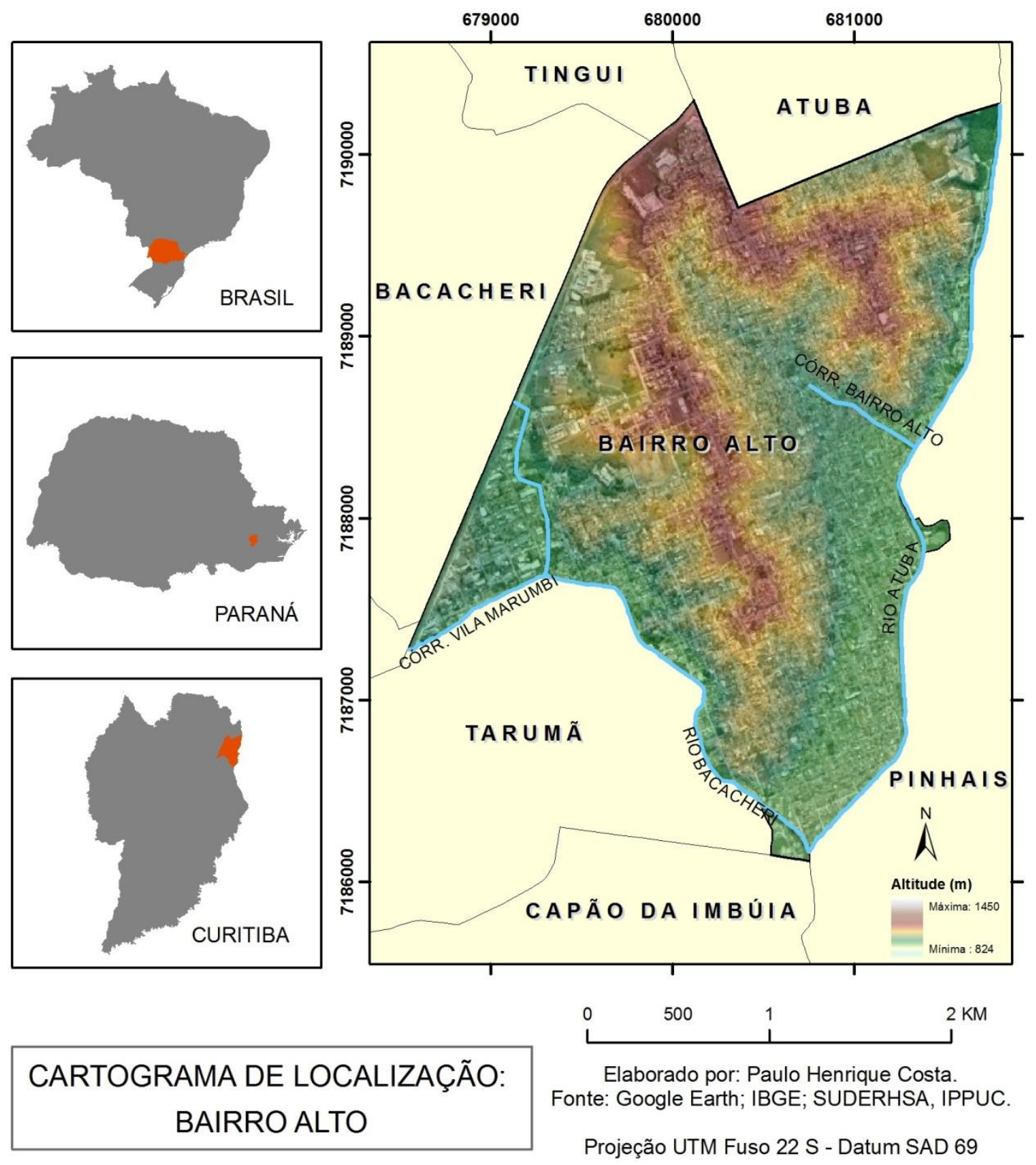

Org.: Paulo Henrique Costa (2014).

Segundo o Instituto de Pesquisa e Planejamento Urbano de Curitiba (IPPUC), o Bairro Alto, até agosto de 2010, possuía sete praças, dez jardinetes, um núcleo ambiental e um bosque (Irmã Clementina) e uma área verde de aproximadamente $264.556 \mathrm{~m}^{2}$ (IPPUC, 2010). Quase todas as ruas são asfaltadas com quadras bastante geométricas seguindo uma mesma orientação (NW-SE), com exceção das 
áreas mais recentemente loteadas ou ainda sem ocupação que se localizam próximo a Linha Verde.

Para a realização do mapeamento de cobertura da terra, utilizou-se o método desenvolvido por Valaski (2013), com adaptações realizadas por Nucci et al. (2014) e que consiste na interpretação de imagens de satélite para classificar a cobertura de cada quadra de um determinado recorte espacial. As classes de cobertura da terra estão apresentadas na figura a seguir (Erro! Fonte de referência não encontrada.).

Figura 2: Legenda para mapeamento da cobertura da terra.

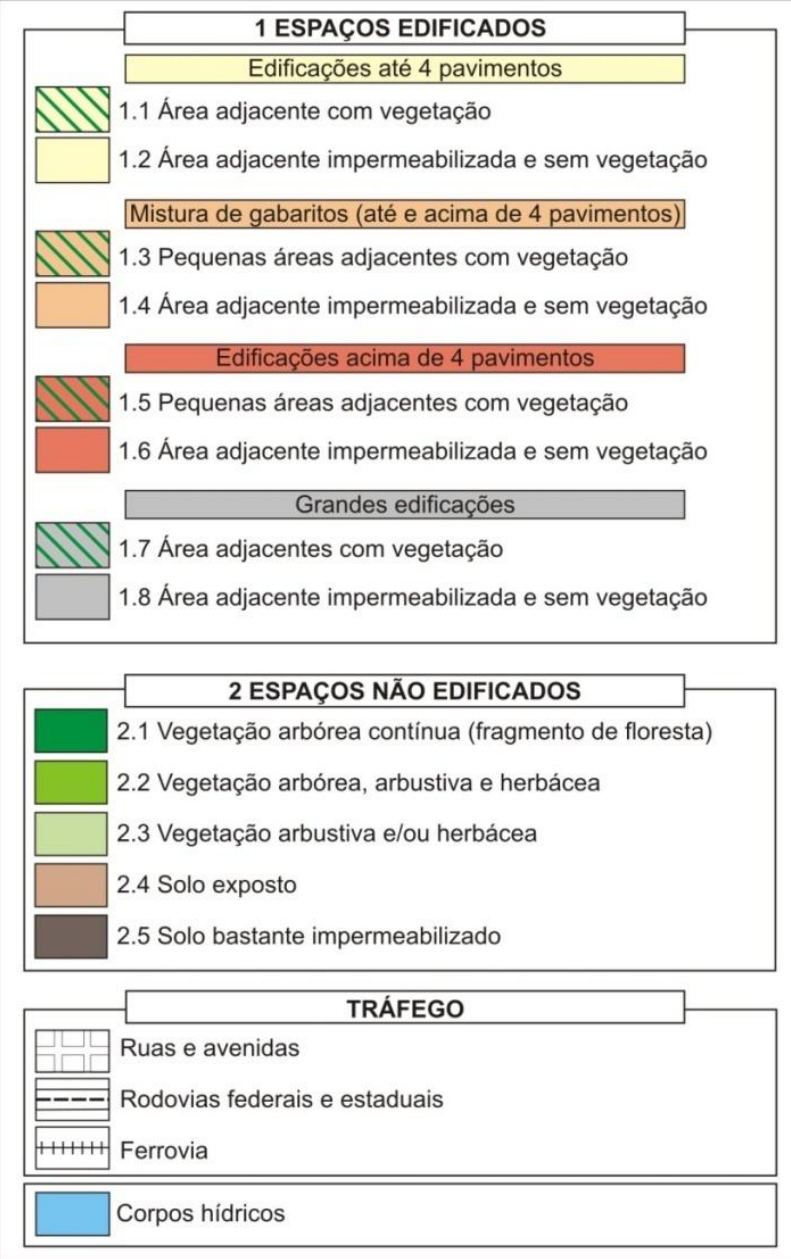

Fonte: Nucci et al. (2014). 
A legenda agrupa as classes em espaços edificados, espaços não edificados e de tráfego. A diferenciação das classes considera o tamanho e o porte das edificações, a existência ou não de vegetação, o tipo de vegetação existente e o tipo de tráfego implantado.

Foram organizadas as bases cartográficas com alguns dos produtos na escala 1:20.000, adquiridos no banco de dados do IPPUC, como a divisão dos bairros e o arruamento. Já a hidrografia foi adquirida da biblioteca virtual do Instituto das Águas do Paraná na escala 1:10.000.

Para a classificação das quadras foram utilizadas duas telas simultâneas, uma mostrando as imagens do Google Earth com escala aproximada de 1.5.000, e outra mostrando as quadras no ArcView com a mesma escala fixada.

A decisão para classificar a quadra baseou-se nas características geométricas predominantes de cada elemento presente, sempre observando os tipos de cobertura dominante e, quando necessário, foram realizadas generalizações, ou seja, foi considerada a classe que mais apareceu dentro do conjunto de lotes que compõem a quadra (Figura 3).

Figura 3: Generalização dos lotes em uma quadra.

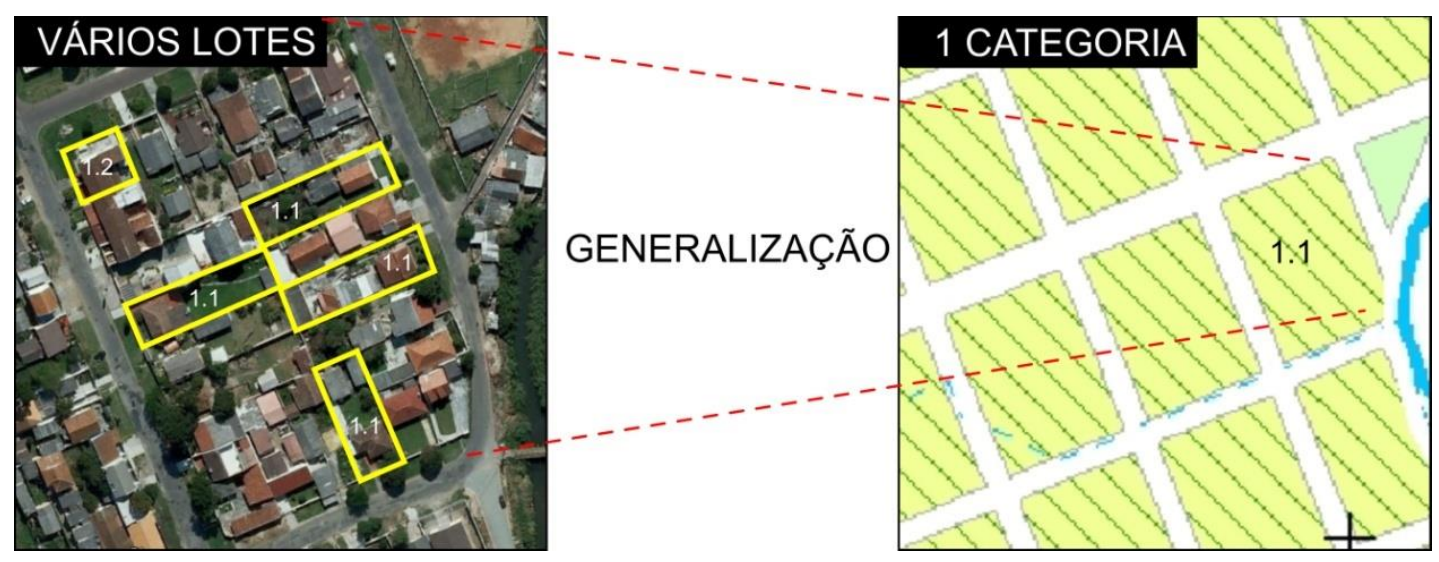

Org: Paulo Henrique Costa (2014).

O mesmo ocorreu na generalização do tema (Figura 4), no qual uma quadra pode ser classificada em vários temas, mas somente aquele mais expressivo, ou 


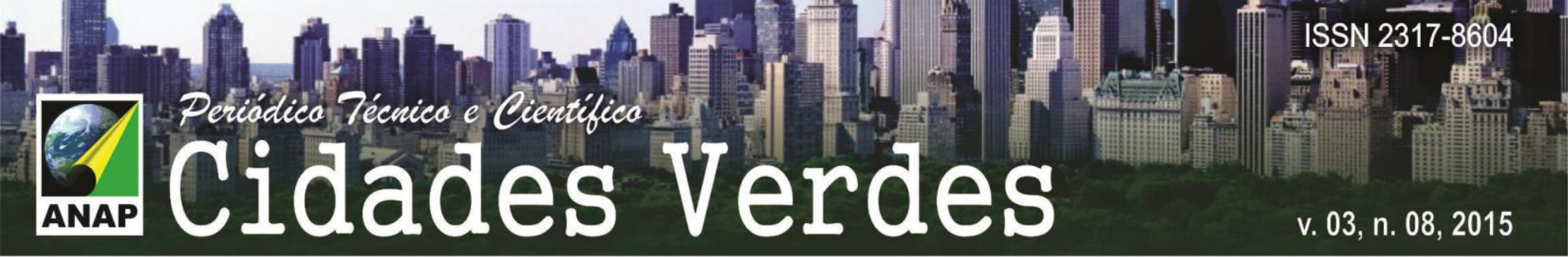

seja, o que ocupa a maior parte da quadra (mais de $60 \%$ da área total da quadra), foi considerado na classificação.

Figura 4: Generalização de categorias dentro de uma quadra.

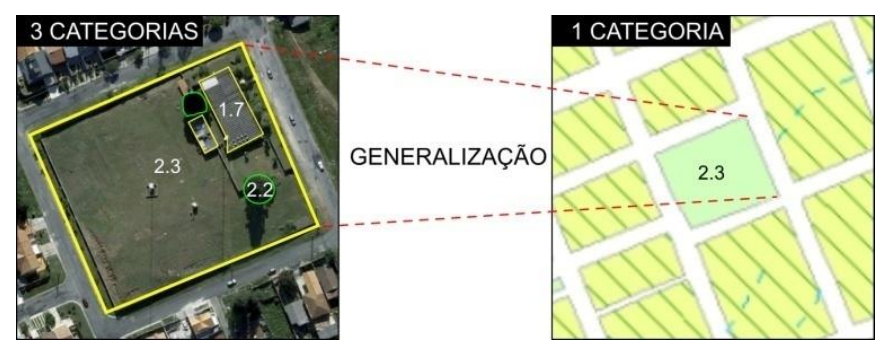

Org: Paulo Henrique Costa (2014).

As características de cada quadra foram associadas a chave de interpretação proposta por Valaski (2013), agrupando-as de acordo com os códigos recomendados na legenda base. Em seguida, foram aplicadas as cores e texturas indicadas na legenda, as convenções cartográficas e demais elementos que compuseram o mapa.

De posse do mapa de cobertura da terra foi possível espacializar a Qualidade Ambiental. A Figura 5 mostra a relação da Cobertura da Terra com a Qualidade Ambiental justificando por meio da dinâmica da paisagem a situação da qualidade ambiental que se apresenta em diferentes níveis indo de melhor para pior. 


\section{.

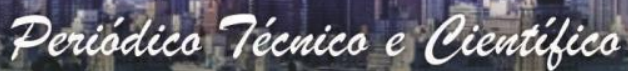 Cidades Verdes

Figura 5: Tipos de cobertura e qualidade ambiental.

\begin{tabular}{|c|c|c|c|c|c|c|c|c|}
\hline & COBERTURA DA TERRA & 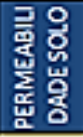 & 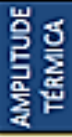 & 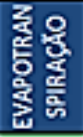 & $\begin{array}{l}\text { 옹 } \\
\text { 영 } \\
\end{array}$ & 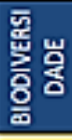 & 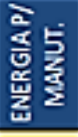 & $\begin{array}{l}\text { QUALIDADE } \\
\text { AMBIENTAL }\end{array}$ \\
\hline & $\begin{array}{l}\text { 3.3 Até } 4 \text { pavimentos } \mathrm{e} \text { áreas adjacentes com } \\
\text { vegetação }\end{array}$ & 2 & 2 & 3 & 3 & 2 & 2 & (1) 14 \\
\hline & $\begin{array}{l}\text { 3.7 Até } 4 \text { pavimentos, com área adjacente } \\
\text { impermeabilizada e sem vegetaçăo }\end{array}$ & 1 & 2 & 1 & 3 & 1 & 2 & (C) 10 \\
\hline 8 & $\begin{array}{l}3.7 \text { Mistura de gabaritos e pequenas áreas } \\
\text { adjacentes com vegetação }\end{array}$ & 2 & 2 & 2 & 2 & 2 & 1 & (C) 11 \\
\hline$\frac{S}{\bar{E}}$ & $\begin{array}{l}\text { 3.4 Mistura de gabaritos e com área adjacente } \\
\text { impermeabilizada e sem vegetação }\end{array}$ & 1 & 1 & 1 & 2 & 1 & 1 & (8) \\
\hline 岁 & $\begin{array}{l}\text { 3.7 Acima de } 4 \text { pavimentos e pequenas áreas } \\
\text { adjacentes com vegetaçăo }\end{array}$ & 2 & 1 & 2 & 1 & 2 & 1 & (ㄱ) \\
\hline घे & $\begin{array}{l}\text { 3.6 Acima de } 4 \text { pavimentos, com área } \\
\text { adjacente impermeabilizada e sem vegetação }\end{array}$ & 1 & 1 & 1 & 1 & 1 & 1 & (2) \\
\hline & $\begin{array}{l}\text { 3.7 Grandes edificaç̄es com vegetaçāo nas } \\
\text { áreas adjacentes }\end{array}$ & 2 & 2 & 2 & 1 & 2 & 1 & (1) 10 \\
\hline & $\begin{array}{l}\text { 3.8 Grandes edficações, com área adjacente } \\
\text { impermeabilizada e sem vegetaçăo }\end{array}$ & 1 & 1 & 1 & 1 & 1 & 1 & (2) \\
\hline 8 & $\begin{array}{l}\text { 7.3 Vegetação arbórea continua (fragmento } \\
\text { de floresta) }\end{array}$ & 3 & 3 & 3 & 3 & 3 & 3 & $\oslash$ \\
\hline 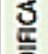 & 7.7 Vegetação arbórea, arbustiva e herbácea & 3 & 3 & 3 & 3 & 2 & 3 & O 17 \\
\hline 岁 & 7.7 Vegetação arbustiva e/ou herbácea & 3 & 2 & 2 & 3 & 2 & 3 & ○ 15 \\
\hline ל্টু & 7.4 Solo exposto & 3 & 2 & 2 & 3 & 1 & 3 & (C) 14 \\
\hline & 7.7 Solo bastante impermeabilizado & 1 & 1 & 1 & 3 & 1 & 3 & (1) 10 \\
\hline
\end{tabular}

Legenda: Sinalização quanto a Qualidade Ambiental:

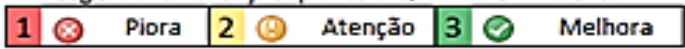

Fonte: Nucci et al.(2014). Org: Paulo Henrique Costa (2014).

\section{RESULTADOS}

O mapa de cobertura do solo (Figura 6) apontou que a maioria das quadras do Bairro Alto foram classificadas como Espaços edificados com até 4 pavimentos com áreas adjacentes com vegetação. 


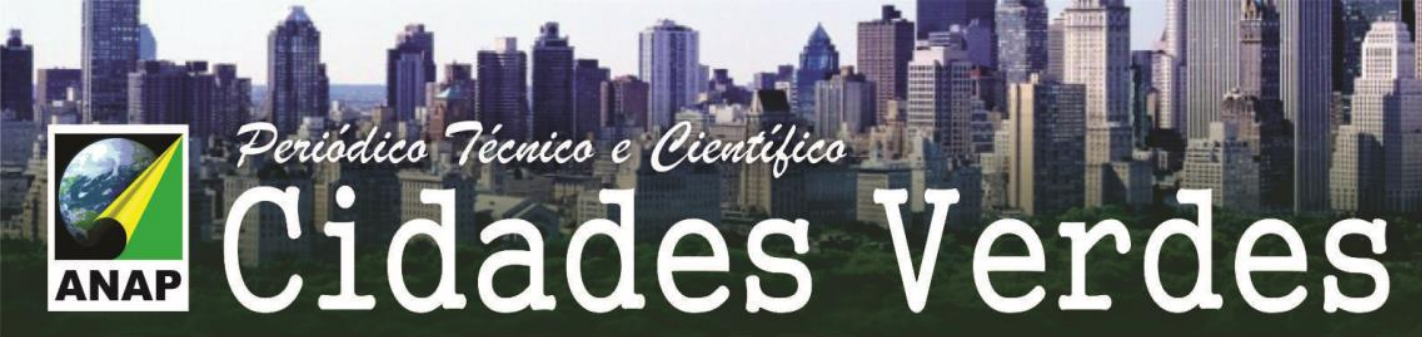

Figura 6: Mapa de cobertura da terra - Bairro Alto (Curitiba-PR).

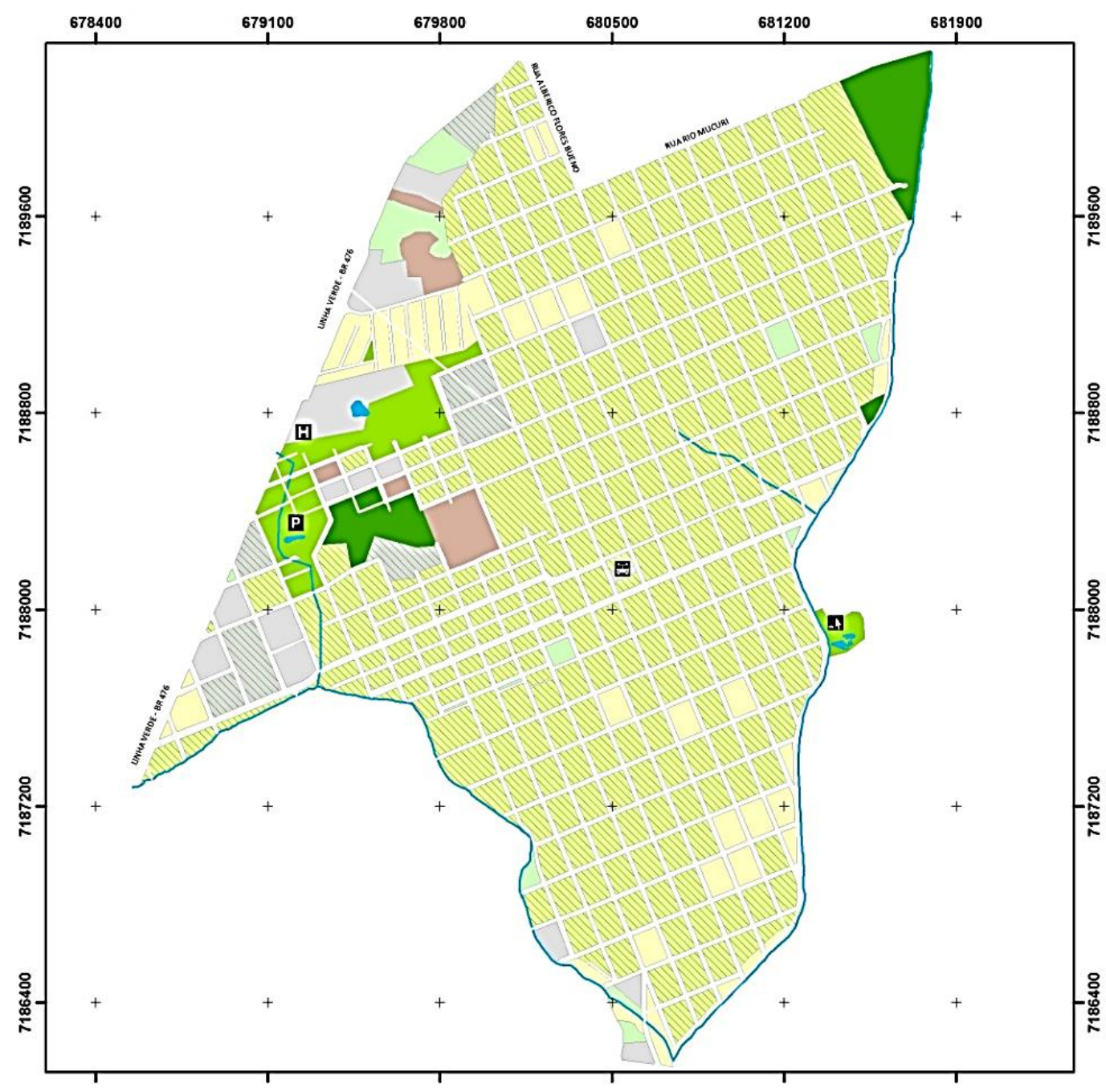

\section{MAPA DE COBERTURA DA TERRA DO BAIRRO ALTO (CURITIBA-PR)}

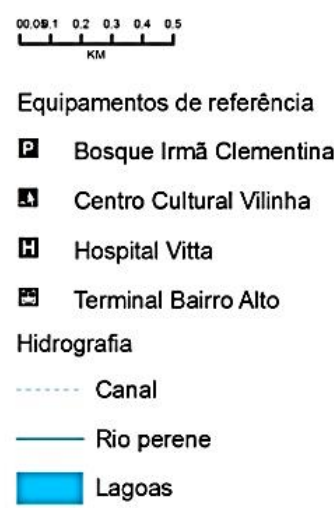

Escala original: 1:22.000

Edificações até 4 pavimentos

AN 1.1 - Área adjacente com vegetação

1.2 - Área adjacente impermeabilizada e sem vegetação Grandes Edificações

A.V 1.7 - Área adjacente com vegetação

1.8 - Área adjacente impermeabilizada e sem vegetação Espaços não edificados

2.1 - Vegetação arbórea contínua (fragmento de floresta)

2.2 - Vegetação arbórea, arbustiva e/ou herbácea

2.3 - Vegetação arbustiva e/ou herbácea

2.4 - Solo exposto (1)

. 


\section{0

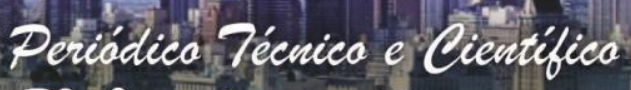

Segundo Valaski (2013) e conforme aponta a Figura 7, esta categoria apresenta pouca infiltração da água da chuva, aumento do escoamento superficial e da amplitude térmica, baixa emissão de poluentes e menor variedade de espécies da fauna. Essas características colocam tais quadras como áreas de qualidade ambiental

média.

Figura 7: Espaços edificados com até 4 pavimentos e presença de vegetação adjacente.

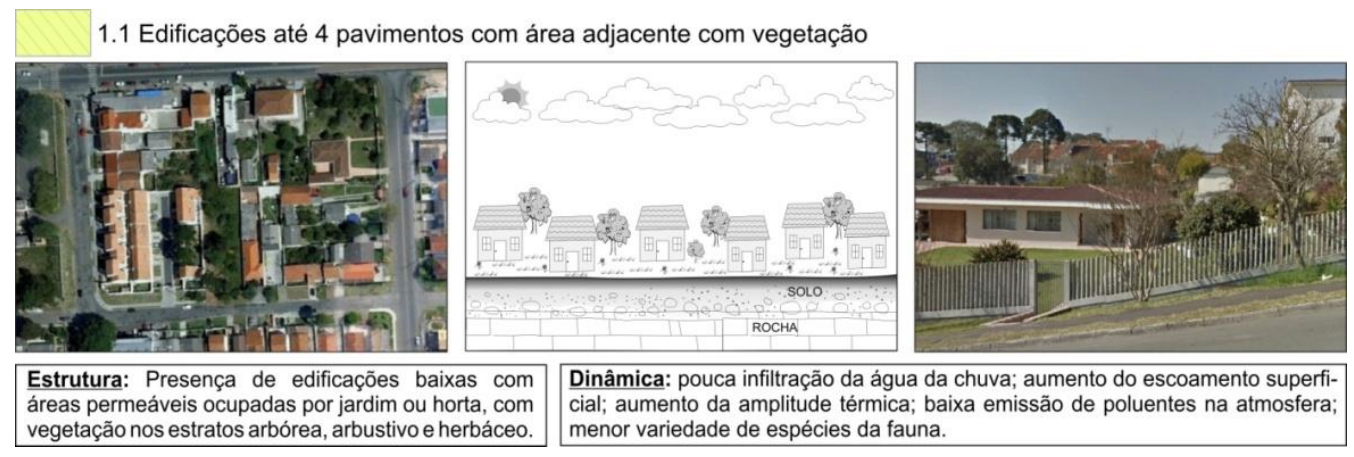

Fonte: Google Earth, Google Street View e Valaski (2013).Org.:Paulo Henrique Costa (2014).

Em contrapartida, nota-se que a região oeste do bairro é marcada pela presença de grandes edificações em relação as demais áreas do bairro. Em algumas quadras não há vegetação adjacente o que caracteriza uma piora significativa na qualidade ambiental já que tais características aumentam a amplitude térmica, o escoamento superficial e a energia para manutenção, como aponta a Figura 8.

Figura 8: Grandes edificações com área adjacente impermeabilizada.

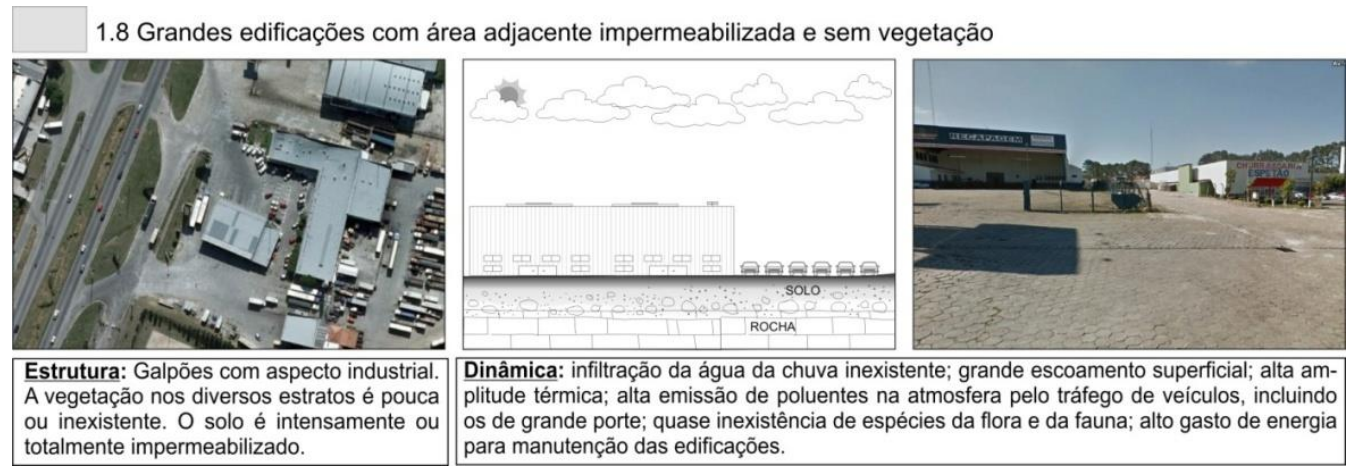

Fonte: Google Earth, Google Street View e Valaski (2013). Org.:Paulo Henrique Costa. 
A área e o percentual de cada categoria foram mensurados, constatando-se que $68 \%$ da área do bairro possuem espaços edificados, $25 \%$ pertencem aos espaços de tráfego e $8 \%$ aos espaços não edificados.

Comparando os resultados com outros locais do Brasil e do mundo, o Bairro Alto possui índices muito inferiores, principalmente a Koege e a Munique. Mesmo comparado a um bairro próximo, o do Bacacheri, mesmo assim o índice de espaços não edificados é muito inferior (Quadro 1).

\section{Quadro 1: Comparativo com outras cidades.}

\begin{tabular}{|c|c|c|c|}
\hline Localidades & Edificados & Não edificados & Tráfego \\
\hline Bairro Alto (Curitiba) & $\mathbf{6 8 \%}$ & $\mathbf{8 \%}$ & $\mathbf{2 5 \%}$ \\
\hline Bacacheri (Curitiba) & $46 \%$ & $30 \%$ & $24 \%$ \\
\hline Rebouças (Curitiba) & $69 \%$ & $3 \%$ & $28 \%$ \\
\hline Berlim (Alemanha) & $45 \%$ & $12 \%$ & $43 \%$ \\
\hline Frankfurt (Alemanha) & $61 \%$ & $25 \%$ & $14 \%$ \\
\hline Koege (Dinamarca) $^{*}$ & $28 \%$ & $42 \%$ & $30 \%$ \\
\hline Munique (Alemanha) & $43 \%$ & $40 \%$ & $17 \%$ \\
\hline
\end{tabular}

* Média das categorias por tipo de residência.

Fonte: Nucci et al. (2014); Pivetta et al. (2005). Org.: Paulo Henrique Costa.

Entretanto, conforme mostra a Figura 9, embora 68\% do bairro estejam classificados com edificações, $78 \%$ dessa parcela são constituídos por gabaritos de até 4 pavimentos com áreas adjacentes com vegetação, o que coloca o Bairro Alto em uma situação melhor que a do Rebouças, cujo estudo feito por Nucci et al (2014), apontou que a existência de espaços edificados com gabaritos de até 4 pavimentos com áreas adjacentes impermeabilizada é muito superior. Isso demonstra que as quadras do Bairro Alto possuem mais vegetação adjacente do que as quadras do Rebouças. 


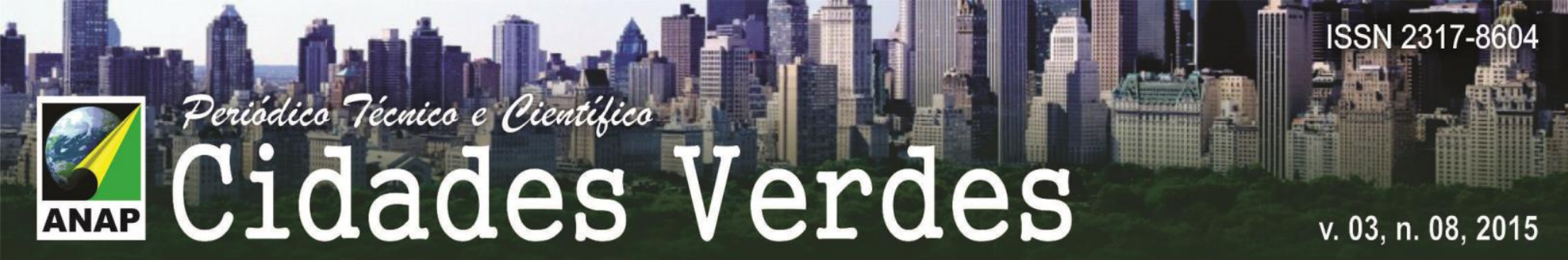

Figura 9: Percentual por tipo de categoria.
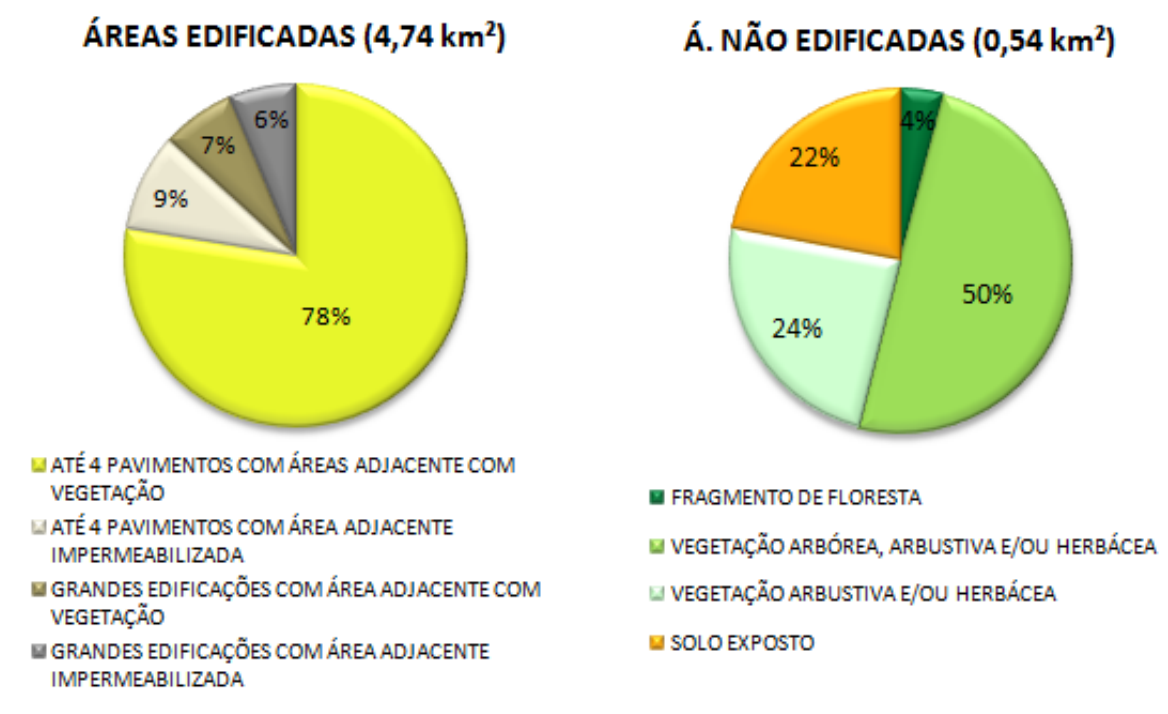

Org.: Paulo Henrique Costa (2015)

A Figura 10 aponta que as regiões com melhor qualidade ambiental estão situadas em áreas públicas como o Bosque Irmã Clementina, Centro Cultural Vilinha e praças do bairro, além de alguns terrenos vazios próximos a Linha Verde. Já a pior qualidade ambiental pode ser encontrada principalmente nas quadras do entorno do Rio Atuba e próximo a foz do Rio Bacacheri, mas na grande parte da região oeste do bairro, na qual a qualidade ambiental já é considerada baixa ou média, a situação poderá piorar nos próximos anos, pois a Lei №. 13.909/2011 (CURITIBA, 2012) ao denominar essas áreas como Linha Verde Polo e Setor especial Linha Verde, promoverá o adensamento e a verticalização de altura livre, o que comprometerá a qualidade ambiental.

Constatou-se também que a região central do bairro está predominantemente coberta por edificações com áreas adjacentes com vegetação, não possuindo nenhum espaço livre que poderiam ser desfrutados pela população. Desse modo, crianças, jovens e idosos precisam se deslocar por várias quadras até o bosque para encontrarem possibilidades de recreação. Uma alternativa seria implantar espaços livres de edificação e com vegetação prioritariamente na região central e noroeste para melhorar a qualidade ambiental. 


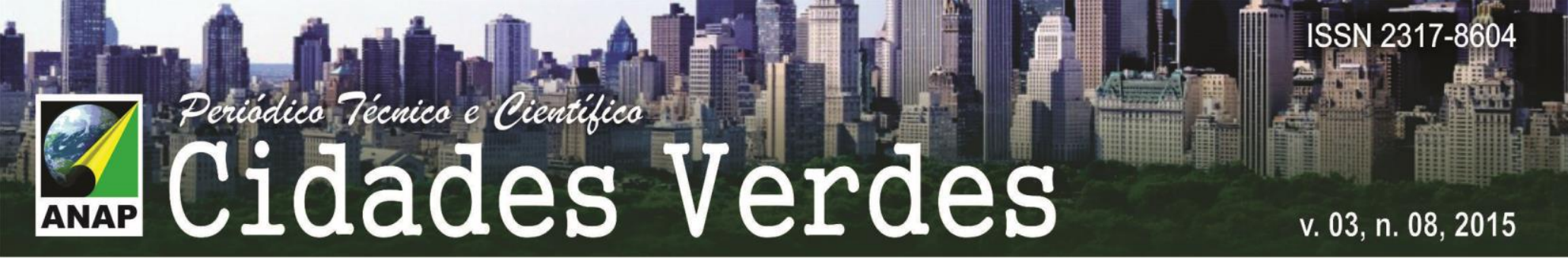

Figura 10: Mapa de qualidade ambiental do Bairro Alto (Curitiba-PR).
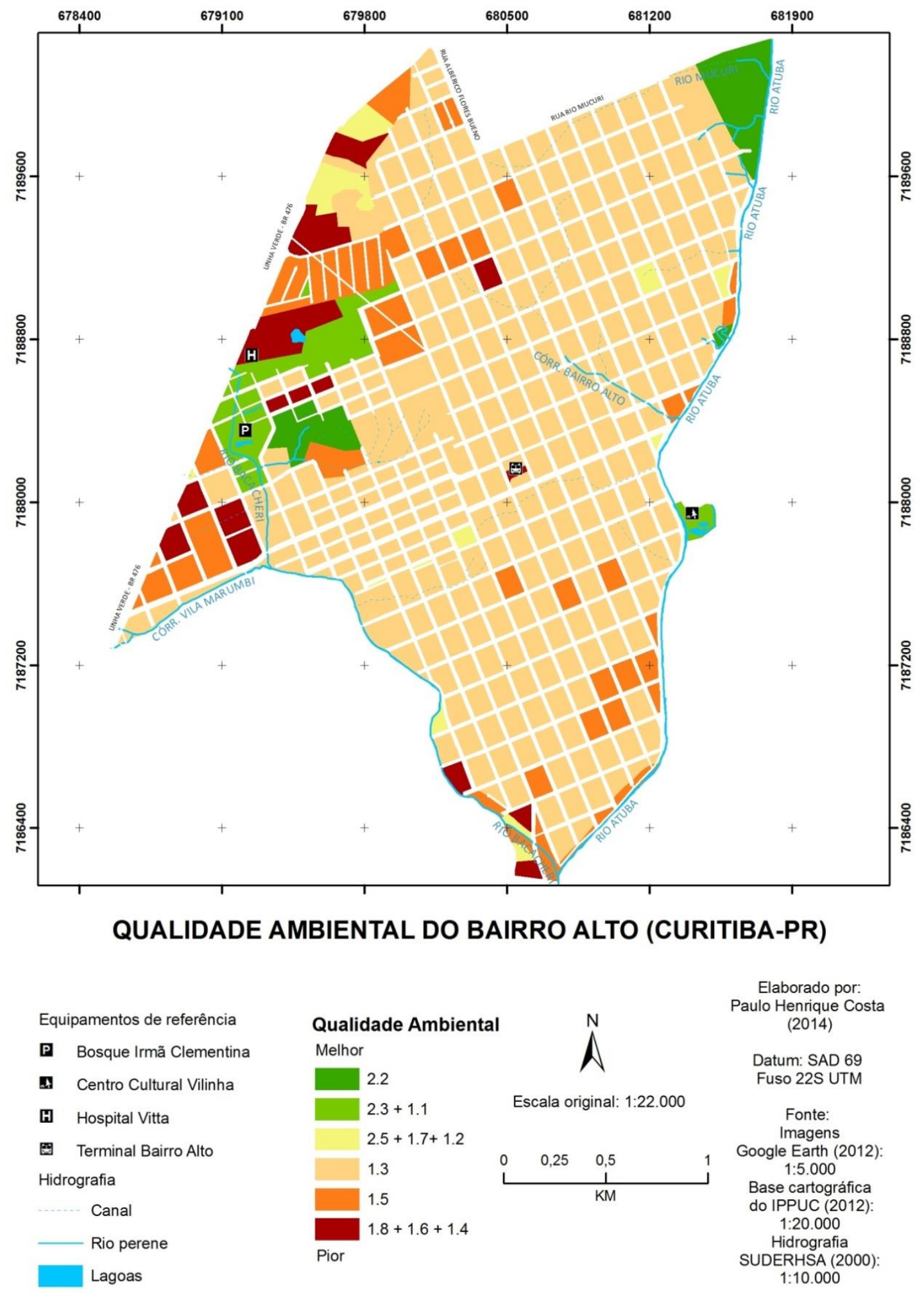

Org.: Paulo Henrique Costa (2014). 
Em relação aos espaços de integração que viária seria aconselhável implantar arborização contínua das ruas, calçadas permeáveis e com boa acessibilidade, galerias pluviais e estímulo a criação de jardins e hortas nos recuos entre as ruas e o início dos lotes, para a melhoria da qualidade ambiental.

\section{CONCLUSÃO}

A legenda simplificada dos tipos de cobertura da terra considerando o tamanho e o porte das edificações, bem como a presença e o porte da vegetação, associado a utilização de tecnologias gratuitas como o Google Earth, conforme propôs Valaski (2013) e Nucci et al. (2014), permitiram classificar as paisagens do Bairro Alto de forma eficiente e didática.

Embora exista um pequeno grau de generalização no reconhecimento de cada quadra, a escala final em que o mapa de cobertura foi apresentado não compromete as informações fundamentais da estrutura e dinâmica da paisagem.

A metodologia proposta por Valaski (2013) também permitiu o reconhecimento dos principais processos da dinâmica da paisagem, favorecendo a possibilidade para se inferir a qualidade ambiental, que, embora seja bastante influenciada pela cobertura da terra, exige a análise de outros parâmetros que não foram contemplados neste trabalho, conforme o fez Nucci (2008).

\section{REFERÊNCIAS BIBLIOGRÁFICAS}

CURITIBA. Prefeitura Municipal de Curitiba. Lei no. 13.909/2011. Uso do Solo. Leis e Decretos Complementares da Legislação de Uso do Solo. IPPUC, 2012.

DEL PICCHIA, P. C. D. O planejamento da Paisagem na cidade. Org. NUCCI, J. C. Planejamento da Paisagem como subsídio a participação popular no desenvolvimento urbano. Estudo aplicado ao bairro de Santa Felicidade - Curitiba/PR. Curitiba LABS/DGEOG/UFPR, 2010. E-book. Disponível em: <http://www.labs.ufpr.br/site/arquivos/Planejamento\%20da\%20Paisagem_ebook_2010.pdf>

DOUGLAS, I.The urban environment.Londres: Edward Arnold (Pub.) Ltda., 1983, 229p.

GEORGE, R. O meio ambiente. Lisboa: Bibliot. Básica de Ciên. Ed. 70, 1984, 112p. 


\section{Períadica Técnica e Cientifica Cidades Verdes}

GRÖNING, G. A questionabilidade do conceito de paisagem. RA'E GA - o espaço geográfico em análise, № 8. Curitiba: Departamento de Geografia - UFPR, 2004, p. 9-18

KIEMSTED, H.; von HAAREN, C.; MÖNNECKE, M.; OTT, S. Landscape Planning: contents and procedures. Hanover: The Federal Ministry for the Environment, Nature Conservation and Nuclear Safety, Universidade de Hanover, 1998, 39p.

INSTITUTO DAS ÁGUAS DO PARANÁ. Disponível em: <http://www.aguasparana.pr.gov.br/>. Acesso em: 02/03/2014.

INSTITUTO DE PESQUISA E PLANEJAMENTO URBANO DE CURITIBA (IPPUC). Disponível em:<http://curitibaemdados.ippuc.org.br/Curitiba_em_dados_Pesquisa.htm>. Acesso em: 03/05/2014.

NUCCI, J. C.; FERREIRA, M. B. P.; VALASKI, S. Cobertura do solo e qualidade ambiental urbana como subsídios ao planejamento da paisagem. VI Congresso Iberoamericano de EstudiosTerritoriales y Ambientales. Anais ... São Paulo, 2014.

$\mathrm{NUCCl}$, J. C. Qualidade ambiental e adensamento urbano: Um estudo de ecologia e planejamento da paisagem aplicado ao distrito de Santa Cecília (MSP). Edição do Autor, 2008. ebook. Disponível em: $<\mathrm{http}: / /$ www.geografia.ufpr.br/laboratorios/labs/arquivos/qldade_amb_aden_urbano.pdf >. Acesso em: 05/03/02014.

NUNES, F. G; RIBEIRO, N.C; FIORI, A.P. Propriedades morfométricas e aspectos físicos da bacia hidrográfica do Rio Atuba: Curitiba - Paraná. VI Simpósio Nacional de Geomorfologia. Anais ... Goiânia. 2006. Disponível em: <http://www.labogef.iesa.ufg.br/links/sinageo/articles/098.pdf>.Acesso em 28/04/2014.

PIVetTA, A.; CARVAlho, J. A.; DAlBeM, R. P.; MOURA, A. R.; NUCCI, J. C. Sistema de classificação da cobertura do solo para fins de comparação entre cidades e bairros. In: XI Simpósio Brasileiro de Geografia Física Aplicada, 2005, São Paulo. Anais... São Paulo:SBGFA, 2005, p. 381392.

VALASKI, S. Avaliação da qualidade ambiental em condomínios residenciais horizontais com base nos princípios do planejamento da paisagem: estudo de caso: bairro Santa Felicidade Curitiba/PR. Curitiba, 2008. 135p. Dissertação (Mestrado em Geografia) - Setor de Ciências da Terra, Universidade Federal do Paraná.

VALASKI, S. Estrutura e dinâmica da paisagem: subsídios para a participação popular no desenvolvimento urbano do município de Curitiba/PR. 144 f. Tese (Doutorado em Geografia) Departamento de Geografia, Universidade Federal do Paraná, Curitiba, 2013. 